\title{
Pulmonary Hypertension in Preterm Infants With Bronchopulmonary Dysplasia
}

\author{
Hyo Soon An, MD, Eun Jung Bae, MD, Gi Beom Kim, MD, Bo Sang Kwon, MD, Jae Suk Beak, MD, \\ Ee Kyung Kim, MD, Han Suk Kim, MD, Jung-Hwan Choi, MD, Chung Il Noh, MD and Yong Soo Yun, MD \\ Department of Pediatrics, Seoul National University Children's Hospital, Seoul National University College of Medicine, Seoul, Korea
}

\begin{abstract}
Background and Objectives: With the increasing survival of preterm infants, pulmonary hypertension ( $\mathrm{PH})$ related to bronchopulmonary dysplasia (BPD) has become an important complication. The aim of this study was to investigate the characteristics and outcome of PH in preterm infants with BPD and to identify the risk factors for PH. Subjects and Methods: We reviewed the records of 116 preterm infants with BPD cared for at a single tertiary center between 2004 and 2008. Results: Twenty-nine (25\%) infants had PH > 2 months after birth. PH occurred initially at a median age of 65 days (range, 7-232 days). Severe BPD, a birth weight $<800$ g, long-term ventilator care and oxygen supplementation, a high ventilator setting, infection, and a patent ductus arteriosus (PDA) were related to $\mathrm{PH}$ based on univariate analysis $(\mathrm{p}<0.05)$. The infants who had longer oxygen supplementation were significantly more likely to have $\mathrm{PH}$ (odds ratio, $18.5 ; 95 \%$ confidence interval, 4.1-84.6; $\mathrm{p}<0.001$ ). PH was improved in $76 \%$ of infants after a median of 85 days (range, 20-765 days). Four infants (14\%) died. The death of 3 infants was attributed to PH. Conclusion: BPD was frequently complicated by $\mathrm{PH}$. Although PH resolved in the majority of infants, $\mathrm{PH}$ in preterm infants with BPD can be fatal. Regular screening for $\mathrm{PH}$ and adequate management are required. (Korean Circ J 2010;40:131-136)
\end{abstract}

KEY WORDS: Hypertension, pulmonary; Infant, premature; Bronchopulmonary dysplasia.

\section{Introduction}

Bronchopulmonary dysplasia (BPD) is a chronic lung disease in preterm infants that occurs following mechanical ventilation and oxygen therapy for acute respiratory distress after birth. Despite improvement in perinatal care, chronic lung disease after preterm birth remains a major problem. BPD is one of the most significant sequelae of neonatal intensive care, affecting approximately 10,000 infants in the United States each year. ${ }^{1)}$

Preterm infants with BPD are at high risk of cardio-

Received: July 2, 2009

Revision Received: August 13, 2009

Accepted: September 3, 2009

Correspondence: Eun Jung Bae, MD, Department of Pediatrics, Seoul National University Children's Hospital, Seoul National University College of Medicine, 101 Daehak-ro, Jongno-gu, Seoul 110-744, Korea

Tel: 82-2-2072-3097, Fax: 82-2-743-3455

E-mail: eunjbaek@snu.ac.kr

(a) This is an Open Access article distributed under the terms of the Creative Commons Attribution Non-Commercial License (http://creativecommons. org/licenses/by-nc/3.0) which permits unrestricted non-commercial use, distribution, and reproduction in any medium, provided the original work is properly cited. vascular sequelae. Pulmonary hypertension (PH), impaired gas exchange due to abnormal vasoregulation, exercise intolerance, systemic hypertension, left ventricular hypertrophy, and development of systemic to pulmonary collateral vessels may complicate the course. ${ }^{23)} \mathrm{PH}$ results in right ventricular hypertrophy (RVH) and cardiomegaly and may lead to right heart failure. ${ }^{4)}$

Even though severe $\mathrm{PH}$ is one of the life-threatening complications in neonates, there are few published studies on the incidence and prognosis of $\mathrm{PH}$ in preterm infants with BPD. The aim of this study was to determine the characteristics and outcome of $\mathrm{PH}$ in preterm infants and identify the risk factors for $\mathrm{PH}$.

\section{Subjects and Methods}

A retrospective study was conducted by reviewing the medical records of all infants $<32$ weeks gestational age born between June 2004 and April 2008 at our hospital.

The diagnosis of $\mathrm{PH}$ was made by echocardiography based on the following criteria: 1) velocity of tricuspid valve regurgitation (TR) $\geq 3 \mathrm{~m} / \mathrm{s}$ in the absence of pul- 
monary stenosis; and 2) flat or left-deviated interventricular septal configuration, and RVH with chamber dilation. Infants with one or both of these findings at $>2$ months of age were characterized as having $\mathrm{PH}$. Seven BPD cases showed echocardiographic evidence of $\mathrm{PH}$ before 1 month of age, and the $\mathrm{PH}$ persisted beyond 2 months of age; they were included in this study. However, infants with the typical 'persistent $\mathrm{PH}$ of the newborn' were excluded. Infants with persistent foramen ovale and patent ductus arteriosus (PDA) were included in the study; however, infants with other congenital heart diseases, congenital diaphragmatic hernias, and meconium aspiration syndrome were excluded. Risk factors that contribute to $\mathrm{PH}$ were analyzed. Improvement of $\mathrm{PH}$ was defined as a TR $\leq 2.5 \mathrm{~m} / \mathrm{s}$, a diminished amount of TR, restoration of interventricular septal configuration, regressed RVH and dilation, and discontinuation of oxygen supplementation therapy.

Definition and grading of BPD were based on JobeBancalari criteria. ${ }^{5)}$ The severity of BPD was graded according to the fraction of inspired oxygen $\left(\mathrm{FiO}_{2}\right)$ or positive pressure ventilation (PPV), as follows: mild BPD, breathing room air; moderate $\mathrm{BPD}$, requiring oxygen supplementation $\left(\mathrm{FiO}_{2}\right.$ of $\left.<0.30\right)$; and severe $\mathrm{BPD}$, requiring $\mathrm{FiO}_{2}$ of $\geq 0.30$ or PPV at 36 weeks gestational age."

\section{Statistical analysis}

Data for infant characteristics were expressed as the median and range or mean plus or minus standard deviation or percentage. Continuous values between the two groups were compared by Student's t-test. Rate and proportion were tested with the chi-square test. Factors with a $\mathrm{p}<0.05$ by univariate analysis were included in the logistic regression analysis. In all analyses, $p<$ 0.05 were considered significant. Statistical analysis was conducted using the Statistical Package for the Social Sciences (SPSS), version 12.

\section{Results}

\section{General characteristics}

One hundred sixteen preterm infants with BPD met the inclusion criteria for this study. The median gestational age at birth was 26.7 weeks (range, 23.4-31.9 weeks), and the median birth weight was $805 \mathrm{~g}$ (range, 430-1,560 g). Thirty-six patients (31\%) were small for gestational age (SGA) at birth, defined as a weight below the 10th percentile for the estimated gestational age. The median age of investigation was 18.5 months (range, 2-48.5 months). The grades of BPD were classified as follows: severe (37\%), moderate (37\%), and mild (26\%). Sixty-eight (59\%) infants had respiratory distress syndrome (RDS) at birth, and 36 (31\%) infants had surgical management for PDA. Seven infants died during the study. The characteristics of the infants studied are presented in Table 1.

\section{Pulmonary hypertension}

Twenty-nine infants with BPD (25\%) met the criteria of $\mathrm{PH}$ beyond 2 months of age. $\mathrm{PH}$ was initially diagnosed at a median postnatal age of 65 days (range, 7-232 days). The median gestational age at birth was 26 weeks (range, 23.9-31.0 weeks), and the median birth weight was $700 \mathrm{~g}$ (range, 430-1,450 g). RDS was diagnosed in 21 patients $(72 \%)$. Severe BPD was diagnosed in 25 infants with $\mathrm{PH}(86 \%)$. Among 116 infants with $\mathrm{BPD}, \mathrm{PH}$ was diagnosed in $58 \%$ of the infants with severe $\mathrm{BPD}, 9.3 \%$ of the infants with moderate $\mathrm{BPD}$, and $0 \%$ of the infants with mild BPD cases (Fig. 1). The occurrence of $\mathrm{PH}$ was positively correlated with the severity of BPD $(\mathrm{p}<0.001)$. The degree of TR on echocardiography was trivial in $8(27.6 \%)$ infants, mild in 13 $(44.8 \%)$ infants, and moderate in $8(27.6 \%)$ infants. Right ventricular dilation or hypertrophy was noted in $20(68.9 \%)$ infants, and 23 infants (79.3\%) exhibited a flat interventricular septum on echocardiography.

\section{Comparison between the infant groups with and without pulmonary hypertension}

The clinical characteristics of the study infants are presented in Table 2 . The mean birth weight of the $\mathrm{PH}$ group was lower than the non-PH group $(\mathrm{p}<0.02)$, al-

Table 1. Characteristics of patients

\begin{tabular}{|c|c|c|c|}
\hline & Number & $\%$ & $\begin{array}{l}\text { Median } \\
\text { (range)* }\end{array}$ \\
\hline Gender & 116 & & \\
\hline Male & 73 & 63 & \\
\hline Female & 43 & 37 & \\
\hline Gestational age at birth (weeks) & & & $\begin{array}{c}26.7 \\
(23.4-31.9)\end{array}$ \\
\hline Birth weight $(\mathrm{g})$ & & & $\begin{array}{c}805 \\
(430-1,560)\end{array}$ \\
\hline Small for gestational age & 36 & 31 & \\
\hline \multicolumn{4}{|l|}{ Birth place } \\
\hline Inborn & 92 & 79 & \\
\hline Outborn & 24 & 21 & \\
\hline Apgar score 1 & & & $3.4 \pm 1.9$ \\
\hline Apgar score 5 & & & $5.5 \pm 1.7$ \\
\hline $\begin{array}{l}\text { In vitro fertilization and embryo } \\
\text { transfer (IVF-ET) }\end{array}$ & 31 & 27 & \\
\hline Singlet & 72 & 62 & \\
\hline Multiplet & 44 & 38 & \\
\hline Respiratory distress syndrome & 68 & 59 & \\
\hline \multicolumn{4}{|l|}{ Bronchopulmonary dysplasia } \\
\hline Mild & 30 & 26 & \\
\hline Moderate & 43 & 37 & \\
\hline Severe & 43 & 37 & \\
\hline Patent ductus arteriosus & 96 & 83 & \\
\hline Surgical treatment & 36 & 31 & \\
\hline
\end{tabular}


though the number of infants with a birth weight $<3$ rd percentile was similar at birth. Severe BPD was more prevalent in the $\mathrm{PH}$ group (86\%) than the non- $\mathrm{PH}$ group $(20 \%, \mathrm{p}<0.001)$. The $\mathrm{PH}$ group was comprised of more infants who had undergone surgery for PDA than the non-PH group ( $48 \%$ vs. $27 \%, \mathrm{p}=0.025$ ). The Apgar score at 5 minutes was lower in the $\mathrm{PH}$ group than in the non-PH group $(4.7 \pm 1.8$ vs. $5.8 \pm 1.6$, respectively, $\mathrm{p}=0.011$ ). The $\mathrm{PH}$ group required more resuscitation at birth than the non-PH group (97\% vs. $79 \%$, respectively, $\mathrm{p}=0.039$ ).

Except for four of the infants, most of the infants had respiratory support, including mechanical ventilator and nasal continuous positive airway pressure

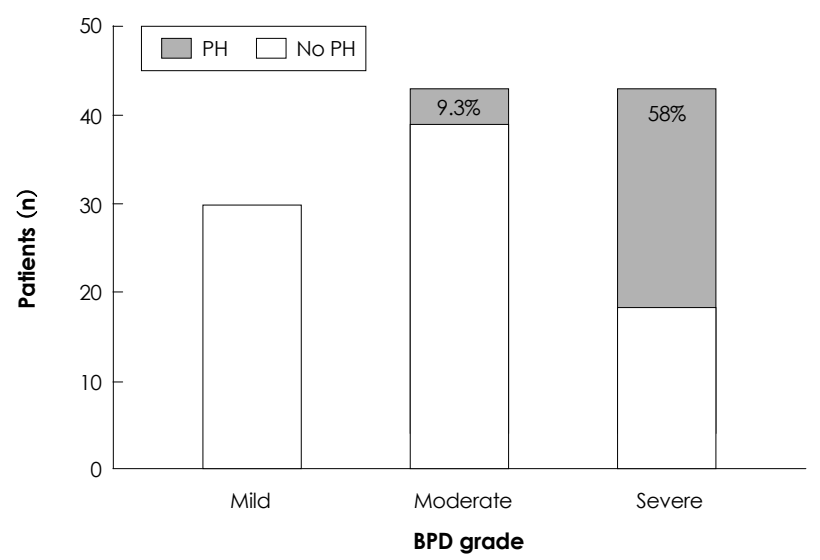

Fig. 1. The occurrence of $\mathrm{PH}$ with the degree of $\mathrm{BPD}$ severity. The occurrence of $\mathrm{PH}$ positively correlated with the degree of BPD severity $(p<0.001)$. PH: pulmonary hypertension, BPD: bronchopulmonary dysplasia.
(CPAP) therapy during admission. The duration of ventilator therapy was longer in the $\mathrm{PH}$ group than in the non-PH group $\{70$ (4-502) days vs. 26 (1-121) days, $\mathrm{p}<$ $0.001\}$. The duration of oxygen supplementation was longer in the $\mathrm{PH}$ group (median, 210 days; range, 75780 days) than in the non- $\mathrm{PH}$ group (median, 82 days; range, $30-510$ days, $\mathrm{p}<0.001)$. The gestational age at discharge was a mean of $44.1 \pm 6.4$ and $40.9 \pm 6.4$ days in the $\mathrm{PH}$ and non-PH groups, respectively $(\mathrm{p}=0.025)$. The postnatal growth was impaired in both groups from birth to discharge (patients with a weight $<3$ rd percentile $13 \% \rightarrow 31 \%, \mathrm{p}<0.001$ in non-PH; $21 \% \rightarrow 61 \%$, $\mathrm{p}<0.001$ in $\mathrm{PH}$ group). The proportion of low-body weight infants $(<3 \mathrm{rd}$ percentile) was higher in the $\mathrm{PH}$ group at the time of discharge $(31 \%: 61 \%, \mathrm{p}=0.009)$.

Severe BPD, birth weight $\angle 800 \mathrm{~g}$, long-term use of ventilator care and oxygen supplementation, application of high-frequency oscillator ventilator (HFO), high positive end expiratory pressure (PEEP) setting on the ventilator, infection during hospitalization (duration of antibiotic use), and PDA requiring surgical closure were related to $\mathrm{PH}$ based on univariate analysis $(\mathrm{p}<0.05)(\mathrm{Ta}-$ ble 3). Infants who had longer oxygen supplementation were significantly more likely to have $\mathrm{PH}$ than the other patients (odds ratio, 18.5; 95\% confidence interval, 4.1-84.6; $\mathrm{p}<0.001)$. Risk factors that contributed to $\mathrm{PH}$ were not identified on multivariate analysis.

\section{Outcome and prognosis}

The median duration of follow-up was 484 days (range, 18-999 days) in infants with PH. PH improved

Table 2. Comparison between BPD patients with and without pulmonary hypertension

\begin{tabular}{|c|c|c|c|}
\hline & Non-PH $(n=87)$ & $\mathrm{PH}(\mathrm{n}=29)$ & $\mathrm{p}$ \\
\hline Gestational age at birth (weeks) & $26.4(23.4-31.9)$ & $26(23.9-31.0)$ & NS \\
\hline Birth weight (g) & $830(510-1560)$ & $700(430-1,450)$ & 0.02 \\
\hline Weight $<3$ rd percentile at birth (\%) & $11(13)$ & $6(21)$ & NS \\
\hline Resuscitation at birth (\%) & $69(79)$ & $28(97)$ & 0.039 \\
\hline Apgar score at $5 \mathrm{~min}$ & $5.8 \pm 1.6$ & $4.7 \pm 1.8$ & 0.011 \\
\hline Male (\%) & $54(62)$ & $19(66)$ & NS \\
\hline Age of mother (years) & $32(24-41)$ & $33(25-40)$ & NS \\
\hline Respiratory distress syndrome (\%) & $47(54)$ & $21(72)$ & 0.082 \\
\hline Necrotizing enterocolitis (operation) (\%) & $14(17)$ & $5(18)$ & NS \\
\hline Retinopathy of prematurity (operation) (\%) & $22(27)$ & $10(39)$ & NS \\
\hline Intracranial hemorrhage (\%) & $20(23)$ & $7(25)$ & NS \\
\hline Duration of $\mathrm{O}_{2}$ use (days) & $82(30-510)$ & $210(75-780)$ & $<0.001$ \\
\hline Duration of ventilator (days) & $26(0-121)$ & $70(4-502)$ & $<0.001$ \\
\hline Dexamethasone* for BPD (\%) & $5(7)$ & $10(35)$ & 0.007 \\
\hline Duration of antibiotics (days) & $21(0-82)$ & $40(16-122)$ & $<0.001$ \\
\hline Duration of Adm (days) & $88(46-187)$ & $133(70-502)$ & $<0.001$ \\
\hline Age of discharge (weeks) & $40.9 \pm 6.4$ & $44.1 \pm 6.4$ & 0.025 \\
\hline Weight $<3$ rd percentile at discharge (\%) & $26(31)$ & $14(61)$ & 0.009 \\
\hline Re-adm. No >1(\%) & $41(58)$ & $16(64)$ & NS \\
\hline
\end{tabular}

Data are median and range, mean $( \pm \mathrm{SD})$ or $\mathrm{n}(\%)$ as appropriate. *dexamethasone rescue therapy was done for severe BPD. BPD: bronchopulmonary dysplasia, Adm: admission, PH: pulmonary hypertension 
Table 3. Factors related to $\mathrm{PH}$

\begin{tabular}{|c|c|c|c|}
\hline & $\begin{array}{l}\text { No PH } \\
(\mathrm{n}=87)\end{array}$ & $\begin{array}{c}\mathrm{PH} \\
(\mathrm{n}=29)\end{array}$ & $\mathrm{p}$ \\
\hline BPD severity & & & $<0.001$ \\
\hline Mild, moderate & 69 & 4 & \\
\hline Severe & 18 & 25 & \\
\hline Birth weight (g) & & & 0.024 \\
\hline$\leq 800$ & 36 & 19 & \\
\hline$>800$ & 51 & 10 & \\
\hline Ventilator care* & & & $<0.001$ \\
\hline$\leq 90$ days & 78 & 21 & \\
\hline$>90$ days & 2 & 8 & \\
\hline PEEP setting on the ventilator ${ }^{\dagger}$ & & & $<0.001$ \\
\hline$\leq 5 \mathrm{cmH}_{2} \mathrm{O}$ & 46 & 7 & \\
\hline$>6 \mathrm{cmH}_{2} \mathrm{O}$ & 26 & 21 & \\
\hline Application of $\mathrm{HFO}$ & & & $<0.001$ \\
\hline No HFO & 74 & 11 & \\
\hline $\mathrm{HFO}$ & 13 & 18 & \\
\hline Oxygen supplementation ${ }^{\neq}$ & & & $<0.001$ \\
\hline$\leq 90$ days & 53 & 2 & \\
\hline$>90$ days & 30 & 23 & \\
\hline $\begin{array}{l}\text { Infection during hospitalization } \\
\text { (duration of antibiotic use) }^{\S}\end{array}$ & & & $<0.001$ \\
\hline$\leq 30$ days & 58 & 7 & \\
\hline$>30$ days & 25 & 22 & \\
\hline PDA requiring surgical closure $"$ & & & 0.025 \\
\hline No OP & 63 & 15 & \\
\hline OP & 22 & 14 & \\
\hline
\end{tabular}

*no PH: continuous positive airway pressure support case $(3$ patients) excluded; no ventilator care (4), ${ }^{\dagger}$ no $\mathrm{PH}$ : continuous positive airway pressure support case (3 patients) excluded; missing data (12), $\mathrm{PH}$ : missing data (1), ${ }^{\ddagger}$ no $\mathrm{PH}$ : missing data (4), $\mathrm{PH}$ : death case (4 patients) exclueded, § no PH: missing data (4), "no PH: missing data (2). PH: pulmonary hypertension, BPD: bronchopulmonary dysplasia, HFO: high-frequency oscillator ventilator, PEEP: positive end expiratory pressure, PDA: patent ductus arteriosus, OP: operation

in 22 infants $(76 \%)$ at a median of 85 (range, 20-765 days) after diagnosis. According to the Kaplan-Meier curve, $\mathrm{PH}$ improved in $68 \%$ of infants by 6 months of age and $73 \%$ of infants by 1 year of age (Fig. 2). Four infants $(14 \%)$ died during the follow-up period. The deaths of 3 of the infants were attributed to $\mathrm{PH}$. The death of the remaining infant was due to respiratory failure as a result of BPD. PH aggravated the condition in 1 infant. Two other patients have shown improved lung condition and are awaiting follow-up echocardiography. The mortality rate of the $\mathrm{PH}$ group was higher than the non-PH group $(14 \%: 3.4 \%, p=0.043)$. Infants with $\mathrm{PH}$ died by a median age of 162 days (range, 70-274 days), which was a median of 117 days (range, 42-190 days) after being diagnosed with PH. In the non-PH group, 3 infants died. One of them died due to sepsis, and the others died because of respiratory failure aggravated by respiratory infection.

Pulmonary vasodilator therapy was used to treat 20

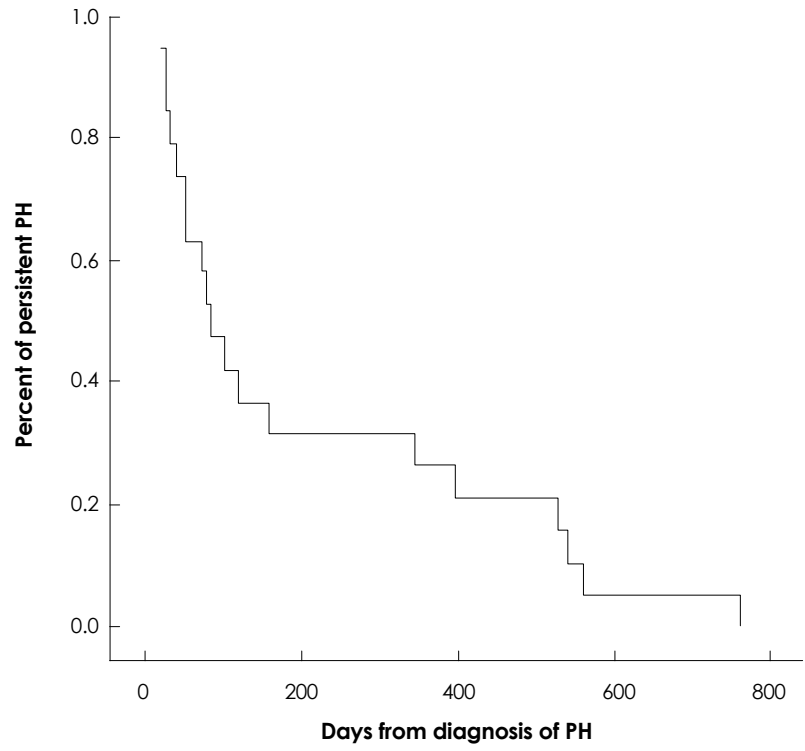

Fig. 2. Kaplan-Meier curve express the resolution of $\mathrm{PH}$. PH improved in $68 \%$ of patients by 6 months and $73 \%$ of patients by 1 year. $\mathrm{PH}$ : pulmonary hypertension.

of the PH infants (69\%), and included the following: inhaled nitric oxide (NO), 13 (44.8\%); sildenafil, 18 (62\%); bosentan, 3 (10.3\%); and iloprost, 4 (13.8\%).

Inhaled NO was used for a median of 39 days (range, 2-173 days). Sildenafil was most often administered at a median of $2.6 \mathrm{mg}$ (range, $0.7-5 \mathrm{mg}) /(\mathrm{kg} \cdot$ day) for a median of 186 days (range, 32-1,129 days). Oxygen supplementation therapy was required for a median of 9.5 months (range, 3-26 months), and PH eventually improved 8.5 months (range, 3.2-29.3 months) later.

\section{Discussion}

Although the mechanisms responsible for elevated pulmonary vascular resistance and altered reactivity remain incompletely understood, the development of $\mathrm{PH}$ is recognized as a serious complication of BPD that can significantly contribute to the morbidity and mortality of preterm infants. ${ }^{67)}$ One study involving 42 preterm infants with BPD complicated by $\mathrm{PH}$ (gestational age $<32$ weeks) reported that $43 \%$ of the infants had severe $\mathrm{PH}$ and the mortality rate was $38 \%{ }^{6}{ }^{6}$ In the current study, it was estimated that the prevalence of $\mathrm{PH}$ among the entire sample of preterm infants with BPD was $25 \%$, and the mortality rate in the $\mathrm{PH}$ group was $14 \%$.

We determined the factors related to $\mathrm{PH}$. The factors, including aggressive mechanical ventilation and high inspired oxygen concentrations are known to be related to BPD. ${ }^{8)}$ There are many common factors between BPD and PH; however, we could not identify the specific risk factors for $\mathrm{PH}$ in preterm infants with $\mathrm{BPD}$ based on multivariate analysis. In BPD, structural abnormalities of the pulmonary vasculature lead to nar- 
rowing of vessel diameters and decreased vascular compliance. Decreased angiogenesis is another consequence of BPD and may contribute to reduce the vascular cross-sectional area. These factors contribute to elevated pulmonary vascular resistance. ${ }^{69)}$ The pulmonary circulation in these patients abnormally respond to oxygen and other pulmonary vasodilators. ${ }^{10}$

$\mathrm{PH}$ affects the growth of preterm infants. There was no difference in the proportion of infants $\leq 3$ rd percentile between the $\mathrm{PH}$ and the non-PH groups at birth. However, at the time of discharge, the proportion of infants $\leq 3$ rd percentile increased significantly in the PH group. Infants with $\mathrm{PH}$ had longer periods of oxygen supplementation and hospital admission than the other infants. The need for treatment can affect the quality of life and the financial status of the infant's family. Although the target systemic arterial oxygen saturation in preterm infants is controversial, long-term supplemental oxygen therapy is the standard treatment for PH-associated BPD. ${ }^{511)}$ There are some reports that elevations in pulmonary arterial pressure persists beyond infancy and early childhood in preterm infants with BPD. ${ }^{1213)}$ The removal of oxygen should be gradual and completed after evaluation of the infant's condition.

In the current study, $\mathrm{PH}$ was diagnosed at a median of 65 days (range, 7-232 days). The gestational age at birth was $24-26$ weeks in $62 \%$ of the infants with $\mathrm{PH}$. Early detection of PH is difficult in children. The diagnosis of $\mathrm{PH}$ in infants and neonates requires a high degree of suspicion because the signs and symptoms of PH may be subtle and non-specific and masked by underlying BPD, even in infants with significantly elevated pulmonary artery pressure. ${ }^{14) 15)}$ However, there are no optimal methods or screening criteria for preterm infants with BPD. Doppler echocardiography is a noninvasive test commonly used to screen and manage $\mathrm{PH}^{1{ }^{16}}$ Echocardiography also has limitations as a screening strategy for $\mathrm{PH}$ in this population. Specifically, echocardiography could fail to detect a measurable TR jet velocity in a significant number of high-risk patients; absence of a TR jet velocity does not rule out the presence of severe $\mathrm{PH}^{.14)}$ In the current study, more than moderate TR on echocardiography was observed in only $28 \%$ of the infants with PH. Because TR is not always measurable, qualitative echocardiographic measures of $\mathrm{PH}$, such as right atrial enlargement, $\mathrm{RVH}$, right ventricular dilation, and septal flattening, seem to have good sensitivity and a positive predictive value for diagnosing $\mathrm{PH}$ in children with chronic lung disease; however, the specificity and negative predictive value are poor. ${ }^{14)}$

After discharge from the hospital, the diagnosis of $\mathrm{PH}$ was confirmed in 4 infants. Although the infants may be well at the time of discharge, symptoms of $\mathrm{PH}$ should be monitored with serial echocardiography.

This study was limited by its retrospective design.
Not every infant with BPD in our institution underwent echocardiography during the study period. The time of diagnosis, improvement, and aggravation may not be precise because the evaluation interval was determined based on the infant's condition.

The number of preterm infants is increasing. Survival, as well as a good quality of life are thought to be important in leading a healthy life. The evaluation and management of complications of BPD are imperative. Preterm infants with BPD must be evaluated periodically for signs and symptoms of $\mathrm{PH}$. More reliable screening methods for $\mathrm{PH}$ and severity stratification are needed. For PH treatment guidelines in preterm infants with chronic lung disease, further prospective randomized controlled studies are warranted in preterm infants with BPD.

\section{REFERENCES}

1) Stenmark KR, Abman SH. Lung vascular development: implications for the pathogenesis of bronchopulmonary dysplasia. Annu Rev Physiol 2005;67:623-61.

2) Abman SH, Accurso FJ, Bowman CM. Unsuspected cardiopulmonary abnormalities complicating bronchopulmonary dysplasia. Arch Dis Child 1984;59:966-70.

3) Gill AB, Weindling AM. Pulmonary artery pressure changes in the very low birthweight infant developing chronic lung disease. Arch Dis Child 1993;68 (3 Spec No):303-7.

4) Goodman G, Perkin RM, Anas NG, Sperling DR, Hicks DA, Rowen M. Pulmonary hypertension in infants with bronchopulmonary dysplasia. J Pediatr 1988;112:67-72.

5) Jobe AH, Bancalari E. Bronchopulmonary dysplasia. Am J Respir Crit Care Med 2001;163:1723-9.

6) Khemani E, McElhinney DB, Rhein L, et al. Pulmonary artery hypertension in formerly premature infants with bronchopulmonary dysplasia: clinical features and outcomes in the surfactant era. Pediatrics 2007;120:1260-9.

7) Fouron JC, Le Guennec JC, Villemant D, Perreault G, Davignon A. Value of echocardiography in assessing the outcome of bronchopulmonary dysplasia of the newborn. Pediatrics 1980;65:529-35.

8) Bancalari E, Claure N. Definitions and diagnostic criteria for bronchopulmonary dysplasia. Semin Perinatol 2006;30:164-70.

9) Subhedar NV. Recent advances in diagnosis and management of pulmonary hypertension in chronic lung disease. Acta Paediatr Suppl 2004;93:29-32.

10) Abman SH, Wolfe RR, Accurso FJ, Koops BL, Bowman CM, Wiggins JW Jr. Pulmonary vascular response to oxygen in infants with severe bronchopulmonary dysplasia. Pediatrics 1985;75: 80-4.

11) Donti A, Formigari R, Ragni L, Manes A, Galie N, Picchio FM. Pulmonary arterial hypertension in the pediatric age. $J$ Cardiovasc Med 2007;8:72-7.

12) Mourani PM, Ivy DD, Gao D, Abman SH. Pulmonary vascular effects of inhaled nitric oxide and oxygen tension in bronchopulmonary dysplasia. Am J Respir Crit Care Med 2004;170:1006-13.

13) Berman W Jr, Yabek SM, Dillon T, Burstein R, Corlew S. Evaluation of infants with bronchopulmonary dysplasia using cardiac catheterization. Pediatrics 1982;70:708-12.

14) Mourani PM, Sontag MK, Younoszai A, Ivy DD, Abman SH. Clinical utility of echocardiography for the diagnosis and management of pulmonary vascular disease in young children with chronic lung disease. Pediatrics 2008;121:317-25. 
15) Kim HW, Kim GB, Je HG, et al. Pulmonary arterial hypertension in children: a single center experience. Korean Circ J 2008; 38:644-50.
16) Bossone E, Bodini BD, Mazza A, Allegra L. Pulmonary arterial hypertension: the key role of echocardiography. Chest 2005;127: 1836-43. 